\title{
The Effectivity of Peer Education Module on Knowledge, Attitude, and Fast Food Consumption in Adolescents
}

\author{
Saskiyanto Manggabarani'), Irfan Said ${ }^{1,2)}$, Anto J. Hadi3), Rapida \\ Saragih4), Muhammad Cristandy5), Neni Ekowati Januariana5)
}

\author{
1)Study Program in Nutrition, Health Institute of Helvetia, Medan, Indonesia \\ ${ }^{2}$ Study Program in Nutrition, School of Health Sciences Pertamedika, Jakarta, Indonesia \\ 3) Masters Program in Public Health, Health Institute of Helvetia, Medan, Indonesia \\ 4)Study Program in Midwifery, Health Institute of Helvetia, Medan, Indonesia \\ 5)Study Program in Public Health, Health Institute of Helvetia, Medan, Indonesia
}

\section{ABSTRACT}

Background: Increasing obesity sufferers every year, in a few decades becomes an important problem. Increased obesity can lead to an increased risk of degenerative diseases which can cause death. Several attempts have been made to prevent and treat obesity. The purpose of this study is to determine the effectiveness of peer education on knowledge, attitudes, and consumption of fast food in adolescents.

Subjects and Method: This study is a randomized controlled trial conducted at a Junior High School (SMP Negeri 6 Medan), North Sumatera. Samples taken were 60 students chosen randomly. The sample was divided into 2 groups: a peer game education leaflet group and a peer education module group. The dependent variable is knowledge, attitudes, and habits of fast food consumption. The independent variable is the provision of leaflets and peer education modules. The data were obtained through interview, Food Frequency Questionnaire (FFQ), and Food Recall 24 hours. Data were analyzed using t-test.

Results: The results showed that the value of nutritional knowledge and obesity in the control group (Mean=12.07; $\mathrm{SD}=1.44$ ) was lower compared to the intervention group $(\mathrm{Mean}=13.5 \mathrm{O}$;
$\mathrm{SD}=1.99)$, but not statistically significant $(\mathrm{p}=$ 0.523 ). Attitudes toward nutrition and obesity in the control group (Mean=11.5O; $\mathrm{SD}=1.22)$ were lower than those in the intervention group (Mean $=13.00 ; \mathrm{SD}=1.78)$ and were statistically proven significant $(\mathrm{p}=0.008)$. The score of fast food consumption habits in the control group (Mean= 8.17; $\mathrm{SD}=1.23$ ) is lower than that of the intervention group (Mean= 9.50; $\mathrm{SD}=1.17)$ and is statistically proven significant ( $\mathrm{p}<0.001)$.

Conclusion: The nutrition peer education module has been shown to be effective in increasing attitudes about nutrition and obesity and reducing fast food consumption habits and this has been statistically significant. The nutrition peer education module increases knowledge scores, but is not statistically significant.

Keywords: obesity, consumption of fast food, peer education

\section{Correspondence:}

Saskiyanto Manggabarani, Helvetia Health Institute, Jl. Kapten Sumarsono No. 107 Medan, North Sumatera, Indonesia. Email: zhakymanggabarani@gmail.com.

Cite this as:

Manggabarani S, Said I, Hadi AJ, Saragih R, Cristandy M, Januariana NE (2020). The Effectivity of Peer Education Module on Knowledge, Attitude, and Fast Food Consumption in Adolescents. J Health Promote Behav. 5(1): 35-43. https://doi.org/10.26911/thejhpb.2020.05.01.05

cc) (7) (2) Journal of Health Promotion and Behavior is licensed under a Creative Commons Attribution-NonCommercial-ShareAlike 4.0 International License.

\section{BACKGROUND}

Obesity has become one of the serious health problems in adolescents (Al-Hazzaa et al., 2014; Lee et al., 2011). Childhood obesity has been increasing continuously in the past four decades. Childhood obesity will likely continue into adulthood and increase the risk of future disease (Oyewande et al., 2019).

Obesity is the fifth leading cause of death in the world. Obesity has become a global issue 
worldwide and was raised by WHO as the biggest chronic health problem. Obesity is caused by several factors, including genetic, socio-economic, behavioral and environmental factors (Lee and Park, 2013). Obesity is one of the main factors causing noncommunicable diseases. Cardiovascular disease, cancer, and diabetes mellitus are non-communicable diseases which are the main causes of morbidity and mortality (Ryu et al., 2014).

The Word Health Organization stated that the world's obesity rate is $11.9 \%$ and more than 1.4 billion adolescents aged 20 years or over suffer from Overweight, and 200 million obese people are boys and 300 million are girls (Nicholls et al., 2014). The prevalence of child overweight and obesity has increased substantially throughout the world in less than a generation. In the United States, the average weight of a child has risen more than $5 \mathrm{~kg}$ in three decades, to the point where one third of the country's children are overweight or obese (Lobstein et al., 2015). The increasing prevalence of adolescent obesity and associated short and long term complications emphasize the need for effective treatment (Steinbeck et al., 2018).

Obesity is one of the complex phenomena that is influenced by genetic, behavioral, environmental, and family factors. The balance between energy intake and expenditure can cause obesity. An environment that encourages lack of physical activity, and consumption of high fat foods, high carbohydrate foods support a positive energy balance. Inadequate physical activity during childhood and adolescence and the influence of the media are risk factors that influence the incidence of obesity in adolescents who are classified as children at the age of "at risk of being overweight (Lubans et al., 2014).

Obesity will become an increasing social and economic burden. Parents and adolescents usually underestimate obesity compared to other chronic diseases so that it can cause a rather negative attitude towards obesity (Nickel et al., 2019). Obesity reflects the state of positive energy balance that results from the interaction of biology and the environment. Environmental conditions that have socioeconomic differences contribute to dietary behavior that can cause weight changes (Fahlman et al., 2010; Wang et al., 2010).

Obesity intervention programs focused on children and parents have a close relationship in increasing knowledge (YackobovitchGavan et al., 2018). A person's knowledge will be able to shape his personality, where each individual has a picture is determined by four factors, namely the physical and mental environment, psychological structure, desires and goals, and experience (Hatta et al., 2018). Some studies suggest that knowledge has a relationship with the incidence of obesity. Many obstacles must be faced to conduct adequate treatment for very obese adolescents, especially changing the attitudes of adolescents (Roebroek et al., 2019).

One method that can be done in increasing knowledge such as the provision of intervention through the media (Bean et al., 2018). For this reason, the purpose of this study is to determine the effectiveness of peer education on knowledge, attitudes, and consumption of fast food in adolescents.

\section{SUBJECTS AND METHOD}

\section{Study Design}

This study is a randomized controlled trial (RCT) conducted at SMP Negeri 6 Medan, North Sumatra, from March to August 2019.

\section{Population dan Sample}

The population is all middle school students. A sample of 60 students aged 11-15 years were selected using random sampling. The sample consists of 60 students chosen randomly. The sample was divided into 2 groups: a peer game education leaflet group (control) and a peer education module group (intervention). 


\section{Study Variables}

The dependent variable is knowledge, attitudes, and fast food consumption habits. The independent variable is the peer education game leaflet and the peer education module.

\section{Operational Definition of Variables}

Knowledge is the result of knowing students have about nutrition and obesity. Data collected by questionnaire. The measurement scale is continuous.

Attitudes toward nutrition and obesity are students' views on food and the risk of obesity. Data were collected using a questionnaire. The measurement scale is continuous.

Fast food consumption habits are a description of the habits of the types of food students often consume according to the fast food category. Data was collected using Food Frequency Questionnaire (FFQ), and 24-hour Food Recall. The measurement scale is continuous.

Body mass index is an assessment of nutritional status by comparing and measuring students' height and weight and calculated with the formula weight (kg) / height2 (m2).

\section{Study Instruments}

The data were obtained by conducting direct interviews with students using a questionnaire. Height and weight measurements were carried out using camry and microtoise brand digital scales. Assessment of fast food consumption habits is done by asking students to fill out the FFQ form and the 2X 24 hour food recall form before and after the intervention.

\section{Data Analysis}

The data were analyzed using $t$ test.

\section{RESULTS}

1. Characteristics of Study Subjects

Based on continuous data, Table 1 shows that the age of adolescents is 11 to 15 years with an average of 12.81. The lowest adolescent body weight was $53.1 \mathrm{~kg}$ and the heaviest weight was $96.6 \mathrm{~kg}$ with an average of 67.61 . The shortest height is $141.6 \mathrm{~cm}$ and the highest is $168 \mathrm{~cm}$. The lowest body mass index is 25 and the highest is 38.7 with an average of 27.89 .

Table 1. Characteristics of continuous data samples

\begin{tabular}{lcccc}
\hline \multicolumn{1}{c}{ Variable } & Mean & SD & Minimum & Maximum \\
\hline Age & 12.81 & 0.87 & 11 & 15 \\
Weight & 67.61 & 9.53 & 53.1 & 96.6 \\
Height & 155.46 & 6.74 & 141.6 & 168 \\
Body Mass Index & 27.89 & 2.9 & 25 & 38.7 \\
\hline
\end{tabular}

Table 2 shows the number of respondents in this study were 60 students, namely 27 male students (45.00\%) and 33 female students (55.00\%). The most age group is 13 years with 28 students (46.7\%). The most weight is 67 to $73 \mathrm{~kg}$ with 18 students (30.0\%).
The highest size height was in the 149-152 cm group, with 15 students (25.0\%) and the lowest was 15 years with 1 student (1.7\%). Body mass index shows that there are 31 overweight students (951.7\%) and 29 obese students (48.3\%). 
Manggabarani et al./ The Effectivity of Peer Education Module

Table 2. Characteristics of categorical data samples

\begin{tabular}{lcc}
\hline \multicolumn{1}{c}{ Characteristics } & Frequency & Percentage \\
\hline Gender & & \\
Male & 27 & $45.0 \%$ \\
Female & 33 & $55.0 \%$ \\
Age & & \\
11 years & 4 & $6.7 \%$ \\
12 years & 16 & $26.7 \%$ \\
13 years & 28 & $46.7 \%$ \\
14 years & 11 & $18.3 \%$ \\
15 years & 1 & $1.7 \%$ \\
Weight & & \\
53 to $59 \mathrm{~kg}$ & 15 & $25.0 \%$ \\
60 to $66 \mathrm{~kg}$ & 14 & $23.3 \%$ \\
67 to $73 \mathrm{~kg}$ & 18 & $30.0 \%$ \\
74 to $80 \mathrm{~kg}$ & 7 & $11.7 \%$ \\
81 to $87 \mathrm{~kg}$ & 4 & $6.7 \%$ \\
88 to $96 \mathrm{~kg}$ & 2 & $3.3 \%$ \\
Height & & \\
141 to $144 \mathrm{~cm}$ & 4 & $6.7 \%$ \\
145 to $148 \mathrm{~cm}$ & 4 & $6.7 \%$ \\
149 to $152 \mathrm{~cm}$ & 15 & $25.0 \%$ \\
153 to $156 \mathrm{~cm}$ & 12 & $20.0 \%$ \\
157 to $160 \mathrm{~cm}$ & 13 & $21.7 \%$ \\
161 to $164 \mathrm{~cm}$ & 5 & $8.3 \%$ \\
165 to $168 \mathrm{~cm}$ & 7 & $11.7 \%$ \\
BMI & & \\
Overweight & 31 & $51.7 \%$ \\
Obesity & 29 & $48.3 \%$ \\
\hline
\end{tabular}

2. Bivariate Analysis

Table 3 shows differences in knowledge scores about nutrition and obesity, nutritional attitud- es and obesity, and fast food consumption habits.

Table 3. Results of independent t-tests of the influence of leaflets and peer education modules on knowledge, attitudes and habits of fast food consumption between control and intervention groups

\begin{tabular}{lccccc}
\hline \multirow{2}{*}{ Variable } & \multicolumn{2}{c}{ Control } & \multicolumn{2}{c}{ Intervention } & \multirow{2}{*}{ p } \\
\cline { 2 - 4 } & Mean & SD & Mean & SD & \\
\hline Nutrition and Obesity Knowledge & & & & & \\
Pre Test & 11.30 & 1.66 & 11.43 & 1.94 & 0.628 \\
Post Test & 12.07 & 1.44 & 13.50 & 1.99 & 0.523 \\
Nutrition and Obesity & & & & & \\
Pre Test & 11.30 & 1.66 & 11.53 & 1.65 & 0.009 \\
Post Test & 11.50 & 1.22 & 13.00 & 1.78 & 0.008 \\
Fast Food Consumption Habits & & & & & \\
Pre Test & 7.93 & 1.44 & 8.87 & 1.11 & 0.001 \\
Post Test & 8.17 & 1.23 & 9.50 & 1.17 & 0.001 \\
\hline
\end{tabular}


Table 3 shows that the score of knowledge about nutrition and obesity in the control group before treatment $($ Mean $=11.30 ; \mathrm{SD}=$ 1.66) is lower than after treatment (Mean= 12.07; $\mathrm{SD}=1.44$ ) whereas in the intervention group, the score of knowledge about nutrition and obesity before treatment $($ Mean $=11.42$; $\mathrm{SD}=1.94$ ) lower than after treatment (Mean= 13.50; $\mathrm{SD}=1.99$ ). However, there was no difference in Mean increase in knowledge about nutrition and obesity in the control group compared with the intervention group with a value $(p=0.523)$.

Attitudes about nutrition and obesity in the control group before treatment (Mean= 11.30; $\mathrm{SD}=1.66$ ) are lower than after treatment (Mean $=11.50 ; \mathrm{SD}=1.22$ ), whereas in the intervention group, score attitudes about nutrition and obesity before treatment (Mean $=11.53$; $\mathrm{SD}=1.65)$ lower than after treatment (Mean = 13.00; $\mathrm{SD}=1.78$ ) and there was a difference in Mean attitudes about nutrition and obesity in the control group compared with the intervention group with a value $(\mathrm{p}=0.008)$.

The fast food consumption habits of the control group before treatment $($ Mean $=7.93$; $\mathrm{SD}=1.44$ ) were lower than after treatment (Mean=8.17; $\mathrm{SD}=1.23$ ), whereas in the intervention group, the fast food consumption habits scores before treatment (Mean = 8.87; $\mathrm{SD}=1.11)$ lower than after treatment (Mean= 9.50; $\mathrm{SD}=1.17$ ) and there were differences in Mean fast food consumption habits in the control group compared with the intervention group with values $(\mathrm{p}<0.001)$.

Based on the Chi-Square test in table 4, it can be seen that knowledge about nutrition and obesity is related to body mass index (OR= 4.22; $p=0.009)$. Attitudes increase obesity but are not statistically significant $(\mathrm{OR}=2.28 ; \mathrm{p}=$ o.126). Fast food consumption habits increase obesity but are not statistically significant $(\mathrm{OR}=2.03 ; \mathrm{p}=0.181)$.

Table 4. Chi-square results of the influence of knowledge, attitudes, and fast food consumption habits on BMI

\begin{tabular}{|c|c|c|c|c|c|c|}
\hline \multirow{3}{*}{ Variable } & \multicolumn{4}{|c|}{ Body Mass Index } & \multirow{3}{*}{ OR } & \multirow{3}{*}{$\mathbf{p}$} \\
\hline & \multicolumn{2}{|c|}{ Overweight } & \multicolumn{2}{|c|}{ Obese } & & \\
\hline & $\mathbf{N}$ & $\%$ & $\mathbf{N}$ & $\%$ & & \\
\hline \multicolumn{7}{|l|}{ Nutrition and Obesity Knowledge } \\
\hline Adequate & 22 & 59.5 & 15 & 40.5 & \multirow{3}{*}{4.22} & \multirow[t]{2}{*}{0.009} \\
\hline Inadequate & 9 & 39.1 & 14 & 60.9 & & \\
\hline \multicolumn{6}{|l|}{ Attitudes Towards Nutrition and Obesity } & \\
\hline Good & 18 & 58.1 & 13 & 41.9 & \multirow{3}{*}{2.28} & \multirow[t]{2}{*}{0.126} \\
\hline Poor & 13 & 44.8 & 16 & 55.2 & & \\
\hline \multicolumn{6}{|l|}{ Fast Food Consumption Habits } & \\
\hline Normal & 14 & 58.3 & 10 & 41.7 & \multirow{2}{*}{2.03} & \multirow[t]{2}{*}{0.181} \\
\hline Unusual & 17 & 47.2 & 19 & 52.8 & & \\
\hline
\end{tabular}

\section{DISCUSSION}

1. Nutrition and Obesity Knowledge

Education can increase knowledge about nutrition and obesity in accordance with the results of this study that there is an effect of providing modules and game leaflets as peer education. Providing peer education regularly through media modules and leaflets containing nutrition and information on the effects of be- ing overweight can add insight to adolescents. Modules provided in book form provide more information, are durable and can be stored and read repeatedly while leaflets in the form of leaflets present simple and easy-to-read material but are easily damaged so it is difficult to read repeatedly. Reading and receiving information repeatedly can retain and enhance adolescent knowledge. 
Good knowledge can also form positive behaviors that will be applied in everyday life, especially in eating patterns. Weight gain often occurs because of a lack of knowledge about the nutritional content of food so that the food consumed does not meet the needs, in fact most consume excess food than the calorie needs per day. Knowing the nutritional content of food can make students avoid the food too much when knowing the impact.

The results of this study are supported by Ashima and Barry who state that education among adolescents is very important, especially to provide an overview of the desired dietary practices to cover the lack of knowledge associated with low levels of education (Kant \& Graubard, 2013).

\section{Attitudes Towards Nutrition and Obe-} sity

Adolescent responses to obesity are very important in the usual eating behavior of children who cannot control their eating habits properly. The results of this study stated that the administration of the module has an effect on the value compared to the leaflet has no effect. More information displayed in the game module has a positive effect such as teenagers can foster a sense of wanting to have a normal weight in order to be able to do activities without feeling shy.

Views on people who have more weight and do not know the negative effects and do not consider it a disease is a factor that will cause obesity. Adolescents who have suffered from obesity have the nature of reluctance to ask questions and shame so that the usual diet program for weight loss is not optimal. This is what we need to provide motivation in order to increase self-confidence and respond to obesity as a disease that must be prevented and treated immediately.

This study is similar to that carried out by those who found that bad attitudes and negative perceptions about risk factors for being overweight and obesity can increase the pre- valence of overweight and obesity (Oyewande et al., 2019). Patients suffering from obesity often experience stigmatization and discrimination which creates a lack of self-confidence that will form behaviors that no longer care about themselves (Nickel et al., 2019). The intervention program carried out can have a positive effect and stimulate changes in good attitude for the prevention of obesity (Bean et al., 2018; Sousa et al., 2019).

\section{Fast Food Consumption Habits}

Ratings in negative food consumption habits are assessed by a score, the higher the score, the lower the teenager consumes fast food per week based on its frequency, and vice versa if the score is low, it means that more adolescents consume fast food per week which indicates that teens usually consume fast food.

Nutrition education through the game module media has an influence on Fast food consumption habits where a value is obtained $(\mathrm{p}=0.010)$ where there is a difference between before and after the intervention is given in the form of peer education game modules.

Reducing adolescent fast food consumption habits due to already having knowledge of the negative effects of consuming excessive fast food. Selection of the type of food that is not right and the availability of foods that contain carbohydrates and high fat can cause a buildup of fat in the body. Excessive consumption of carbohydrates and fats is also due to the tendency to consume foods which are more trendserving foods that are low in other nutrients. Exposure to fast food in the home or school environment which is supported by online ordering facilities also triggers the desire to buy these foods.

Students must be educated about the negative effects of frequent consumption of fast food and get used to eating food cooked at home (Shaban and Alkazemi, 2019). Adolescent eating patterns, including snacking habits and fast food consumption have differences before and after given peer peer education model in- 
tervention (Hadi et al., 2019). Family habits that eat fast food together are risk factors for obesity and the same results for families who order from outside the home for their children (Alturki et al., 2018).

The limited knowledge possessed by adolescents can be a mistake in determining the method taken in weight loss. Incorrect referral results in unsuccessful weight loss programs which have an effect on adolescent attitudes no longer concerned with the condition of his body. Concern is what led to the consumption of food that no longer controls the type of food consumed. Peer education has an influence on behavior change in adolescents.

\section{AUTHOR CONTRIBUTION}

Saskiyanto Mangg Stephani, and Anto J. Hadi played a role in initiating ideas, making proposals and instruments, intervening, and writing articles. Irfan Said, Rapida Saragih, and Muhammad Cristandy played a role in the administration of research, data collection and compilation and making the final report. Neni Ekowati Januariana was instrumental in the analysis and interpretation of data.

\section{CONFLICT OF INTEREST}

There was no conflict of interest in this study.

\section{FUNDING AND SPONSORSHIP}

This study was supported by a research grant from the Directorate of Research and Community Service, Directorate General of Research and Development Strengthening with a contract number T/135/L1.3.1/PT.01.03 /2019 on April 25, 2019.

\section{ACKNOWLEDGEMINT}

Authors would like to thank the Directorate of Research and Community Service, Directorate General of Research and Development Strengthening and SMPN 6 Medan.
REFERENCE

Al-Hazzaa HM, Al-Sobayel HI, Abahussain NA, Qahwaji DM, Alahmadi MA, Musaiger AO (2014). Association of dietary habits with levels of physical activity and screen time among adolescents living in S audi A rabia. Journal of Human Nutrition and Dietetics, 27: 204-213. https://doi.org/10.1111/jhn.12147.

Alturki HA, Brookes DS, Davies PS (2018). Comparative evidence of the consumption from fast-food restaurants between normal-weight and obese Saudi school children. Public Health Nutrition, 21(12): 2280-2290. https://doi.org/10.1017/S1368980018000757.

Bean MK, Ingersoll KS, Powell P, SternM, Evans RK, Wickham III EP, MazzeoSE (2018). Impact of motivational interviewing on outcomes of an adolescent obesity treatment: Results from the MI Values randomized controlled pilot trial. Clinical Obesity, 8(5): 323-326. https://doi.org/10.1111/cob.12257

Fahlman MM, McCaughtry N, Martin J, Shen B (2010). Racial and socioeconomic disparities in nutrition behaviors: Targeted interventions needed. Journal of Nutrition Education and Behavior, 42(1): 10-16. https://doi.org/10.1016/j.jneb.2008.11.003.

Hadi AJ, Hadju VS, Indriasari R, Manggabara S, Yetti RE, et al. (2019). The effect of the implementation of a planned peer group session model on obesity prevention among students of an Integrated Islamic primary school in Makassar. Pakistan Journal of Nutrition, 18(9): 882-887. https://doi.org/10.3923/pjn.2019.882.8 87.

Hatta H, Hadi AJ, Tombeg Z, Manggabarani S (2018). The relationship between food selection factors for students at Maccini Sombala Inpres Elementary School Makassar City. Window of Health: Jurnal K- 
Manggabarani et al./ The Effectivity of Peer Education Module

esehatan, 355-363. https://doi.org/10.33368/woh.v1i4.112

Kant AK, Graubard BI (2013). Family income and education were related with 30-year time trends in dietary and meal behaviors of American Children and Adolescents-3. The Journal of Nutrition, 143(5): 690700. https://doi.org/10.3945/jn.112.165258.

Lee HA, Lee WK, Kong KA, Chang N, Ha EH, Hong YS, Park H (2011). The effect of eating behavior on being overweight or obese during preadolescence. Int J Prev Med, 44(5): 226. https://doi.org/10.3961/jpmph.2011.44.5.226.

Lee HA, Park H (2013). Overview of noncommunicable diseases in Korean children and adolescents: Focus on obesity and its effect on metabolic syndrome. Journal of Preventive Medicine and Public Health, 46(4): 173. https://doi.org/10.3961/jpmph.2013.46.4.173.

Lobstein T, Jackson-Leach R, Moodie ML, Hall KD, GortmakerSL, Swinburn BA, et al. (2015). Child and adolescent obesity: part of a bigger picture. The Lancet, 385(9986): 2510-2520. https://doi.org/10.1016/So140-6736(14)61746-3.

Lubans DR, Smith JJ, Skinner G, Morgan PJ (2014). Development and implementation of a smartphone application to promote physical activity and reduce screen time in adolescent boys. Frontiers in Public Health, 2: 42. https://doi.org/10.3389/fpubh.2014.00042.

Nicholls L, Lewis AJ, PetersenS, Swinburn B, Moodie M, Millar L (2014). Parental encouragement of healthy behaviors. BMC Public Health, 14(1): 369. https://doi.org/10.1186/14712458-14369.

Nickel F, Tapking C, Benner L, Schüler S, Ottawa GB, Krug K, et al. (2019). Video teaching leads to improved attitudes towards obesity a randomized study with 949 participants. Obesity Surgery, 29(7):
2078-2086. https://doi.org/10.1007/s11695-019-03804-9

Oyewande A, Ademola A, Okuneye T, Sanni F, Hassan A, Olaiya P (2019). Knowledge, attitude and Perception regarding risk factors of overweight and obesity among secondary school students in Ikeja Local Government Area, Nigeria. Journal of Family Medicine and Primary Care, 8(4): 1391. https://doi.org/10.4103/jfmpc.jfmpc_160_19.

Roebroek YGM, Talib A, Muris JWM, van Dielen FMH, Bouvy ND, van Heurn LWE (2019). Hurdles to take for adequate treatment of morbidly obese children and adolescents. World Journal of Surgery, 43(4): 1173-1181. https://doi.org/10.1007/soo268-018-4874-5.

Ryu SY, Park J, Choi SW, Han MA (2014). Associations between socio-demographic characteristics and healthy lifestyles in Korean adults: The result of the 2010 community health survey. Journal of Preventive Medicine \& Public Health, 47(2): 113-123. https://doi.org/10.3961/jpmph.2014.47.2.113

Shaban L, Alkazemi D (2019). Trends in fastfood consumption among Kuwaiti youth. International Journal of Preventive Medicine, 10. https://doi.org/10.4103/ijpvm.IJPVM_480_18.

Sousa P, Duarte E, Ferreira R, Esperança A, Frontini R, Santos-Rocha, et al. (2019). An mHealth intervention programme to promote healthy behaviours and prevent adolescent obesity (TeenPower): A study protocol. Journal of Advanced Nursing, 75(3): 683-691. https://doi.org/10.1111/jan.13905.

Steinbeck KS, Lister NB, Gow ML, Baur LA (2018). Treatment of adolescent obesity. Nature Reviews Endocrinology, 14(6): 331-344. https://doi.org/10.1038/s41574-018-0002-8.

Wang Y, Jahns L, Tussing-Humphreys L, Xie 
Manggabarani et al./ The Effectivity of Peer Education Module

B, Rockett H, Liang H, Johnson L (2010). Dietary intake patterns of low income urban African-American adolescents. J Am Diet Assoc, 110(9):1340-1345. https://doi.org/10.1016/j.jada.2010.06.005. Yackobovitch-Gavan M, Wolf Linhard D, Nagelberg N, Poraz I, Shalitin S, Phillip
M, Meyerovitch J (2018). Intervention for childhood obesity based on parents only or parents and child compared with follow-up alone. Pediatric Obesity, 13(11): 647-655. https://doi.org/10.1111/ijpo.12263 